\title{
PERANCANGAN APLIKASI PENCATATAN TRANSAKSI KEUANGAN DAN INVENTORY BERBASIS ANDROID DISTRIBUTOR PRODUK MSL PURBALINGGA
}

\author{
Ali Nur Ikhsan, Adam Prayogo Kuncoro, Alfiansyah Arifudin Akbar \\ Program Studi Informatika, Universitas Amikom Purwokerto \\ J1. Let.Jend.Pol. Sumarto, Purwokerto Utara, Banyumas, Jawa Tengah \\ alinurikhsaneamikompurwokerto.ac.id, \\ adameamikompurwokerto.ac.id, fianakbar68@gmail.com
}

\begin{abstract}
The MSL Purbalingga distributor is located in Dusun IV Wanakerta, Banjarkerta, Karanganyar sub-district, Purbalingga district, Central Java. The products available at the MSL Purbalingga Distributor include softeners and fragrances, liquid detergents, softeners, and super laundry perfume. The product prices are determined based on the type of containers, such as bottles, refills, and sprays. But currently, the administration system at the MSL Purbalingga Distributor still uses records in the form of ledgers so that there are deficiencies, namely the accumulation of book archives and transaction record data is less secure. The process of recording transactions and making administration reports within a certain period of time is difficult and even creates administrative problems. With the development of Android technology, it can be used in recording transactions for the MSL Distributor with the aim of simplifying administration, as well as in business matters. In terms of simplifying business affairs, information technology can be used as an administrative recording medium for MSL Distributors in carrying out all aspects of sales transaction activities. The current research focuses on the design and implementation of transaction recording and inventory applications at the location of the Purbalingga MSL agent distributor. The results of the application of this mobile application for recording transactions and inventory are a benefit for research partners, namely, it makes it easier to record and store data compared to the old method of recording using manual books. The application of this mobile application was declared successful after the testing process was carried out at the research partner's location by applying the Black Box testing method.
\end{abstract}

Keywords - Android Mobile Application, Cloud Computing, Application Collecting

\begin{abstract}
Abstrak - Distributor MSL Purbalingga terletak di Dusun IV Wanakerta, Banjarkerta, Kec. Karanganyar, Kab. Purbalingga, Jawa Tengah. Produk yang tersedia pada Distributor MSL Purbalingga diantaranya pelicin dan pewangi, detergen cair, softener, dan parfum laundry super. Harga produk ditentukan berdasarkan jenis wadah, seperti botol, refill dan spray. Tetapi saat ini sistem pembukuan pada Distributor MSL Purbalingga masih menggunakan pencatatan berupa buku besar sehingga terdapat kekurangan yaitu penumpukan arsip buku serta data catatan transaksi kurang aman. Proses pencatatan transaksi dan pembuatan laporan pembukuan dalam kurun waktu tertentu sulit dilakukan, bahkan menimbulkan permasalahan administrasi. Dengan perkembangan teknologi android dapat dimanfaatkan dalam kegiatan pencatatan transaksi Distributor MSL dengan tujuan mempermudah administrasi, serta dalam urusan bisnis. Dalam hal mempermudah urusan bisnis, teknologi informasi dapat dijadikan media pencatatan administrasi bagi Distributor MSL dalam menjalankan segala aspek aktifitas transaksi penjualan. Penelitian saat ini berfokus pada perancangan dan implementasi aplikasi pencatatan transaksi dan inventory di lokasi Distributor agen MSL Purbalingga. Hasil pada penerapan aplikasi mobile pencatatan transaksi dan inventory ini menjadi manfaat bagi mitra penelitian yaitu memudahkan pencatatan serta penyimpanan data dibandingkan dengan metode pencatatan yang lama menggunakan buku manual. Penerapan aplikasi mobile ini dinyatakan berhasil setelah dilakukan proses pengujian di lokasi mitra penelitian, dengan menerapkan metode Black Box testing.
\end{abstract}

Kata Kunci - Aplikasi Mobile Android, Cloud Computing, Aplikasi Pendataan

\section{PENDAHULUAN}

Sistem informasi saat ini sangat mendukung proses bisnis pada suatu organisasi atau perusahaan. Organisasi atau perusahaan dapat menjamin kualitas data yang disajikan serta dapat mengambil keputusan berdasarkan pengolahan data tersebut sehingga menjadi suatu informasi [1]. Pencarian informasi saat ini dapat diperoleh dengan lebih mudah dan cepat, berkat adanya dukungan perkembangan teknologi informasi. Sistem transaksi keuangan dan inventory barang merupakan salah satu contoh dampak positif dari penerapan teknologi informasi yang dirasakan oleh masyarakat [2].

Pelayanan jasa laundry adalah suatu bisnis di bidang jasa pencucian pakaian yang banyak dijumpai di tengah masyarakat. Usaha jasa laundry bermodalkan mesin cuci dan mesin pengering otomatis dengan menggunakan cairan pembersih dan pewangi yang 
dibuat secara khusus. Distributor MSL Purbalingga terletak di Dusun IV Wanakerta, Banjarkerta, Kec. Karanganyar, Kab. Purbalingga, Jawa Tengah merupakan sebuah tempat usaha yang menjual cairan pembersih dan pewangi khusus untuk laundry. Produk yang tersedia pada Distributor MSL Purbalingga diantaranya pelicin dan pewangi, detergen cair, softener, dan parfum laundry super. Adapun produk pembersih lainnya, seperti sabun cuci piring, pembersih lantai, dan pembersih keramik. Harga produk ditentukan berdasarkan jenis wadah, seperti botol, refill, dan spray.

Tetapi saat ini sistem pembukuan pada Distributor MSL Purbalingga masih menggunakan pencatatan berupa buku besar sehingga terdapat kekurangan yaitu penumpukan arsip buku serta data catatan transaksi kurang aman. Proses pencatatan transaksi dan pembuatan laporan pembukuan dalam kurun waktu tertentu sulit dilakukan, bahkan menimbulkan permasalahan administrasi. Dengan perkembangan teknologi android dapat dimanfaatkan dalam kegiatan pencatatan transaksi Distributor MSL dengan tujuan mempermudah administrasi, serta dalam urusan bisnis. Dalam hal mempermudah urusan bisnis, teknologi informasi dapat dijadikan media pencatatan administrasi bagi Distributor MSL dalam menjalankan segala aspek aktifitas transaksi penjualan. Produk yang dijual oleh Distributor MSL Purbalingga tertera pada Gambar 1.

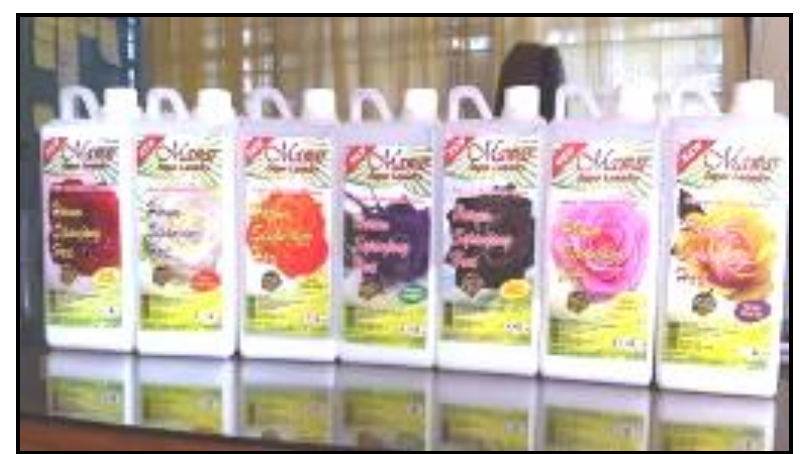

Gambar 1. Gambar produk MSL Purbalingga.

Berdasarkan hasil observasi di lokasi Distributor MSL Purbalingga, terdapat permasalahan dalam melakukan pencatatan administrasi, transaksi dan data stok barang. Saat ini hanya menggunakan pencatatan secara manual pada buku trasnsaksi saja. Sehingga pemilik Distributor MSL Purbalingga memerlukan sebuah apikasi yang difungsikan untuk mencatat pembukuan transaksi bisnis MSL hingga pencatatan gudang barang.

Penelitian saat ini berfokus pada perancangan dan implementasi aplikasi pencatatan transaksi dan inventory di lokasi Distributor agen MSL Purbalingga. Ditujukan aplikasi tersebut untuk memudahkan proses bisnis pada Distributor MSL Purbalingga. Diharapkan aplikasi yang dibuat ini dapat dikembangkan dengan fasilitas yang lebih bagus dan efektif.
Aplikasi pencatatan transaksi dan pendataan stok gudang di Distributor produk MSL Purbalingga menggunakan basis aplikasi mobile android dan menggunakan cloud database guna memudahkan penyimpanan data terkait aplikasi. Dengan diterapkan aplikasi berbasis mobile android di lokasi mitra penelitian, diharapkan mampu meningkatkan tingkat efektifan proses bisnis.

\section{METODE PENELITIAN}

\section{A. Pustaka Teori}

Aplikasi adalah media alat bantu berupa perangkat lunak yang berfungsi sebagai pemecah masalah bagi penggunanya. Aplikasi berasal dari kata aplication yang mempunyai arti penerapan, lamaran, penggunaan. Aplikasi secara istilah merupakan program siap pakai yang dibuat untuk melaksanakan suatu fungsi bagi pengguna atau aplikasi yang lain digunakan untuk tujuan tertentu. Istilah aplikasi biasanya juga dipasangkan dengan suatu perangkat lunak [3]. Media ini diperlukan untuk dapat diterapkan secara efektif di lokasi mitra penelitian. Berfungsi sebagai aplikasi pencatatan transaksi dan inventory stok barang.

Aplikasi mobile adalah aplikasi yang mampu berjalan atau digunakan kapanpun dan dimanapun walaupun penggunanya dalam keadaan bergerak [4]. Pada umumnya perangkat mobile berupa handphone, PDA, Tablet PC, Laptop, serta perangkat komunikasi lainnya. Dengan perangkat tersebut, maka pengguna dapat melakukan komunikasi dengan orang lain melalui media suara/audio, dapat saling mengirim dan menerima pesan tertulis, mengirimkan media gambar atau video [5].

Pengertian tentang aplikasi mobile dapat diartikan sebagai suatu media perangkat lunak yang disematkan ke dalam perangkat mobile, merupakan suatu sistem komputasi yang dengan mudah dapat melakukan transaksi data dan secara kemampuan komputasi dapat digunakan saat penggunanya sedang melakukan aktivitas secara berpindah tempat. Contoh dari perangkat dan aplikasi mobile yaitu personal digital assistant (PDA), smartphone serta ponsel [6]. Aplikasi mobile dapat dibedakan menjadi beberapa kelompok, antara lain:

a. Short Message Service (SMS) merupakan aplikasi mobile yang sederhana, dirancang untuk berkirim pesan teks dan berguna ketika terintegrasi dengan jenis aplikasi perangkat mobile lainnya[7].

b. Mobile Websites (Situs Web Mobile) merupakan situs web yang dirancang untuk dapat diakses melalui perangkat mobile. Situs web mobile sering memiliki desain tampilan sederhana dan berguna untuk memberikan informasi [7].

c. Mobile Web Application (Aplikasi Web Mobile) merupakan aplikasi mobile yang tidak perlu diinstal atau dikompilasi pada perangkat 
penggunanya. Akses yang menggunakan XHTML, CSS dan JavaScript, aplikasi ini mampu memberikan pengguna pengalaman layaknya aplikasi native/asli [7].

Native Application adalah suatu aplikasi mobile yang harus digunakan pada perangkat penggunanya. Aplikasi ini juga dapat dikatakan aplikasi platform, karena aplikasi ini harus dikembangkan dan disusun untuk setiap perangkat secara khusus [8]. Metode native application yang akan digunakan pada pembuatan aplikasi mobile di penelitian ini. Contoh aplikasi yang digunakan untuk android serta dapat diinstal pada perangkat mobile diilustrasikan pada Gambar 2

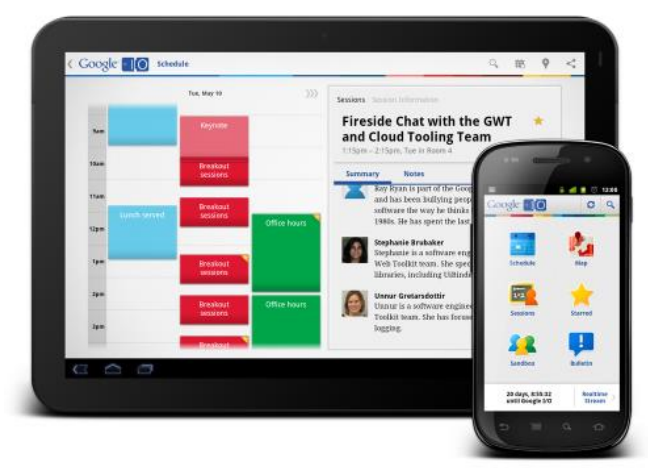

Gambar 2. Ilustrasi aplikasi mobile.

Sistem operasi android dirancang secara terbuka agar mudah diakses bagi para pengembang untuk menciptakan aplikasi mereka sendiri yang digunakan oleh bermacam piranti bergerak [9]. Android dirancang dengan akses terbuka sehingga sebuah aplikasi dapat memanggil fungsi lain pada inti ponsel seperti membuat suatu panggilan, mengirim sebuah pesan teks, mengakses kamera, dan lain sebagainya.

Android memanfaatkan suatu mesin virtual yang dirancang khusus untuk mengoptimalkan perangkat keras dan memori yang terdapat di dalam perangkat [10]. Android merupakan sistem yang dirancang terbuka, dapat secara bebas disebarluaskan untuk dimanfaatkan teknologi baru pada saat teknologi tersebut muncul. Platform ini akan berkembang secara berkelanjutan untuk membangun aplikasi mobile yang inovatif [11].

\section{B. Alur Tahap Penelitian}

Alur tahap penelitian ini diilustrasikan pada Gambar 3 berikut. Diawali dari tahap identifikasi masalah, analisa kebutuhan sistem, perancangan desain aplikasi, pengembangan aplikasi dengan penyematan fitur cloud computing, pengujian aplikasi, serta penerapan, hingga pembuatan pelaporan.

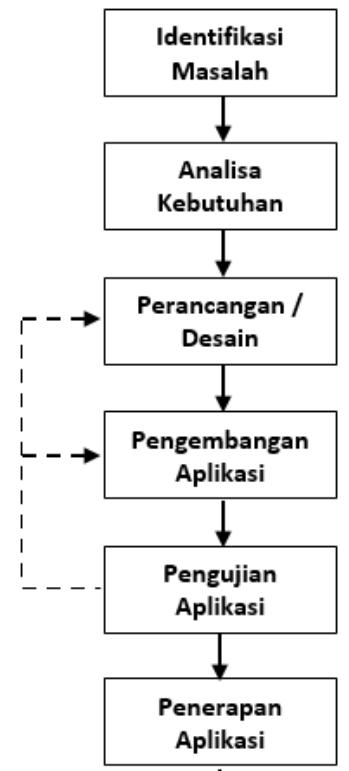

Gambar 3. Alur tahap penelitian. berikut:

Penjabaran keterangan terkait Gambar 3 sebagai

a. Identifikasi masalah. Melakukan pengamatan secara langsung pada lokasi objek penelitian untuk mengetahui hal-hal yang perlu dan akan dilakukan terkait pemecahan masalah terkait kebutuhan sistem penunjang administrasi perkantoran. Pada tahap ini seluruh anggota penelitian melakukan observasi, kemudian merumuskan permasalahan dan solusi yang tepat.

b. Analisa kebutuhan. Tahap analisa kebutuhan dilakukan untuk menyusun fitur-fitur yang akan diterapkan ke dalam aplikasi pendataan administrasi disesuaikan dengan kebutuhan serta solusi dari masalah yang ada di lokasi objek penelitian. Tahap analisa kebutuhan sistem ini menjadi tugas seluruh anggota penelitian.

c. Perancangan desain aplikasi. Pada tahap ini dilakukan perancangan alur pengguna, alur data, skema aplikasi, desain antar muka, hingga perancangan fitur. Tahap ini menjadi tugas seluruh anggota penelitian.

d. Pengembangan aplikasi. Setelah proses perancangan, kemudian dilakukan pengkodean dan pembuatan aplikasi sesuai kebutuhan objek penelitian. Pengembangan aplikasi berupa penggunaan pusat data cloud database, serta perencanaan pengembangan dapat dilakukan pada penelitian berikutnya. Tahap pengembangan aplikasi merupakan tugas seluruh anggota penelitian.

e. Pengujian aplikasi. Proses pengujian aplikasi dilakukan 2 (dua) tahap. Fase pengujian alpha test yaitu uji aplikasi secara internal dan fase beta test merupakan pengujian di lokasi objek penelitian. Pada tahap ini dilakukan oleh semua anggota peneliti. 
Penerapan aplikasi. Pasca tahap pengujian kemudian aplikasi diterapkan di lokasi mitra penelitian. Seluruh alur penggunaan aplikasi dan semua fitur harus dipastikan sudah berhasil digunakan.

\section{HASIL DAN PEMBAHASAN}

\section{A. Analisa Kebutuhan Fungsional}

Tahap ini merupakan fase untuk menganalisa kebutuhan mitra terhadap kebutuhan fungsional aplikasi. Antara lain yaitu:

a. Mampu melakukan proses input kategori, satuan, barang, dan harga.

b. Mampu menampilkan informasi barang dan informasi harga.

c. Mampu menambahkan data barang masuk, barang keluar, pemasukan, dan pengeluaran.

d. Mampu menampilkan laporan barang, laporan pesanan, laporan keuangan, dan grafik penjualan.

e. Mampu menghapus data dan backup data.

Adapun informasi kebutuhan fitur yang diperlukan untuk mendukung proses transaksi dan inventory pada mitra penelitian telah dirangkum pada data Tabel 1 berikut ini.

Tabel 1. Rangkuman analisa kebutuhan

\begin{tabular}{|l|l|}
\hline \multicolumn{1}{|c|}{ Kategori } & \multicolumn{1}{c|}{ Jenis Fitur } \\
\hline \multirow{4}{*}{ Catatan stok gudang } & Data produk \\
\cline { 2 - 2 } & Barang masuk \\
\cline { 2 - 2 } & Barang keluar \\
\cline { 2 - 2 } Catatan transaksi & Data stok barang \\
\hline \multirow{5}{*}{} & Pembelian stok barang \\
\cline { 2 - 2 } & Penjualan stok barang \\
\cline { 2 - 2 } & Transaksi barang retur \\
\cline { 2 - 2 } & Riwayat seluruh transaksi \\
\hline
\end{tabular}

\section{B. Perancangan Alur Proses Aplikasi}

Konsep alur proses aplikasi ini digunakan oleh admin sebagai pengelola data. Serta terdapat 3 (tiga) fitur halaman utama, antara lain yaitu input data, data transaksi dan menu pengaturan.

Menu utama input data berfungsi sebagai masukan data produk dan data item yang tersimpan atau stok barang. Menu data transaksi digunakan untuk pencatatan pemasukan dan pengeluaran pada proses bisnis MSL Purbalingga. Menu pengaturan merupakan fitur untuk mengatur beberapa fitur data pada aplikasi, contohnya seperti reset password, proses backup data, serta menu petunjuk penggunaan aplikasi.

Gambaran penjelasan 3 (tiga) fitur halaman tersebut diilustrasikan pada Gambar 4 berikut.

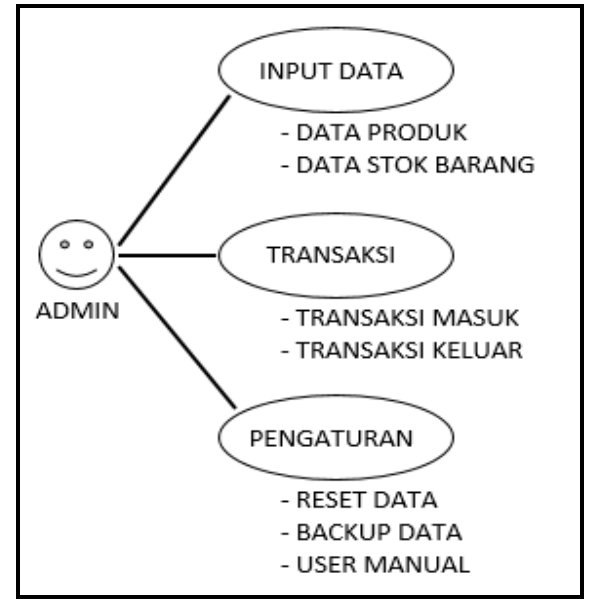

Gambar 4. Rancang alur menu aplikasi.

Di dalam menu Input Data terdapat menu kategori, satuan, barang, harga, informasi harga, dan informasi barang. Pada proses input data barang admin harus mengisi data kategori dan data satuan, dimana kedua data tersebut akan disimpan kedalam sistem kemudian akan ditampilkan pada menu barang dan menu harga. Pada menu barang, admin memilih data kategori dan data satuan serta memasukan varian dan jumlah stok. Data yang telah diinputkan pada menu barang akan tersimpan dan ditampilkan secara detail pada menu informasi barang. Sedangkan pada menu harga, admin memilih data kategori dan data satuan serta memasukan harga barang. Data yang telah diinputkan pada menu harga akan tersimpan dan ditampilkan secara detail pada menu informasi harga.

Proses aktivitas admin saat mengakses menu Transaksi, di dalamnya terdapat menu barang masuk, barang keluar, pemasukan, dan. Pada menu barang masuk, admin memilih data kategori, data satuan, dan data varian serta memasukkan jumlah stok barang sesuai jumlah stok yang akan ditambahkan. Data yang telah diinputkan akan tersimpan kedalam sistem. Lalu pada menu barang keluar, admin memasukan nama mitra, tanggal serta memilih data kategori, data satuan, dan data varian beserta jumlahnya, kemudia sistem akan secara otomatis merekap jumlah total varian dan juga harga. Data yang telah diinputkan akan tersimpan kedalam sistem. Kemudian pada menu pemasukan, admin memasukan nama mitra dan tanggal transaksi lalu sistem akan secara otomatis menampilkan total harga. Data yang telah diinputkan akan tersimpan kedalam sistem. Pada menu pengeluaran, akan secara otomatis menampilkan saldo, saldo ini didapatkan dari pemasukan. Dalam menu pengeluaran, admin memasukan tanggal transaksi, harga, dan juga keterangan transaksi. Data yang telah diinputkan akan tersimpan kedalam sistem.

Di dalam menu Pengaturan terdapat menu reset data, petunjuk penggunaan, dan backup data. Pada menu reset data, sistem akan menampilkan konfirmasi reset data. Jika admin memilih ya, maka semua data akan kereset, jika tidak akan kembali ke menu 
pengaturan. Lalu pada menu petunjuk, sistem akan menampilkan cara menggunakan aplikasi. Dan pada menu backup data, sistem akan menampilkan konfirmasi backup data. Jika memilih ya, maka semua data akan tersimpan, jika tidak akan kembali ke menu pengaturan.

\section{Desain Antar Muka}

Desain antar muka berfungsi sebagai acuan perancangan konsep tampilan aplikasi. Beberapa konsep tampilan yang menjadi halaman penting antara lain yaitu beranda terdiri dari beberapa menu pilihan utama, menu transaksi, menu laporan, serta menu pengaturan.

a. Desain halaman beranda.

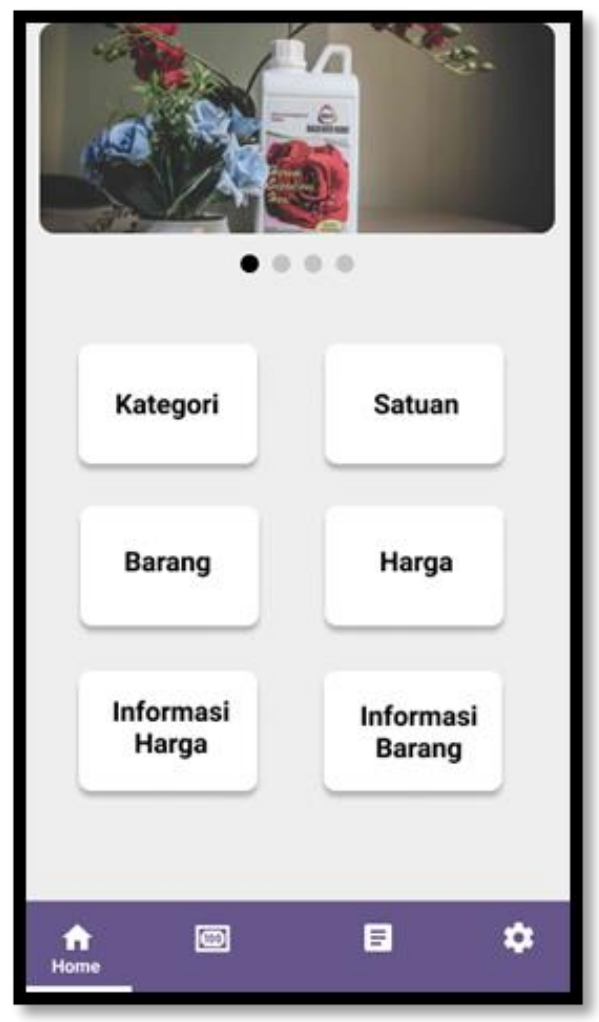

Gambar 5. Konsep halaman beranda.

Desain halaman Beranda pada Gambar 5 digunakan untuk mengolah semua data yang dibutuhkan oleh menu yang lainnya, didalam menu master terdapat menu kategori, satuan, barang, harga, informasi harga, informasi barang. b. Desain halaman menu transaksi.

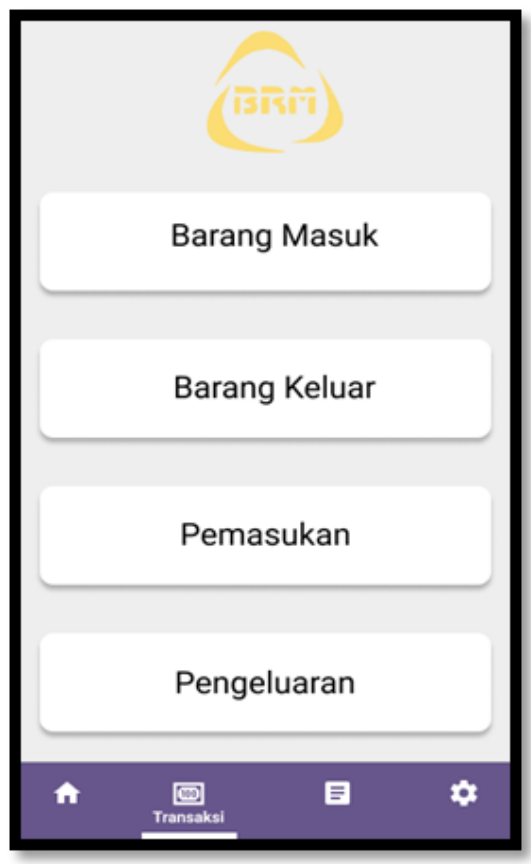

Gambar 6. Konsep halaman menu transaksi.

Konsep halaman menu Transaksi diilustrasikan pada Gambar 6 digunakan untuk mengolah data transaksi barang. Di dalam menu transaksi terdapat menu barang masuk, barang keluar, pemasukan dan pengeluaran.

c. Desain menu laporan.

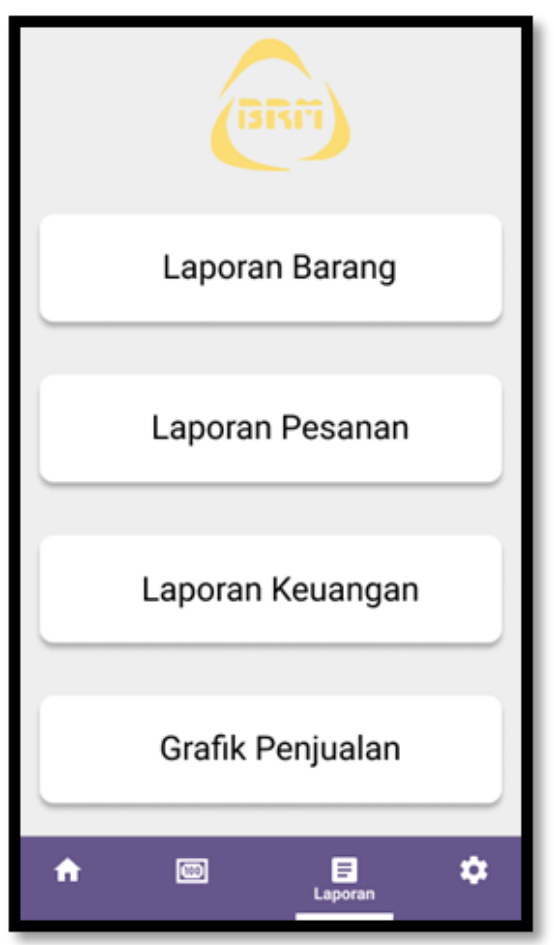

Gambar 7. Konsep halaman menu laporan. 
Gambar 7 merupakan desain halaman menu Laporan digunakan untuk melihat semua laporan dari menu transaksi. Di dalam menu ini terdapat beberapa menu, antara lain laporan barang, laporan pesanan, laporan keuangan, dan grafik penjualan.

d. Desain menu pengaturan.

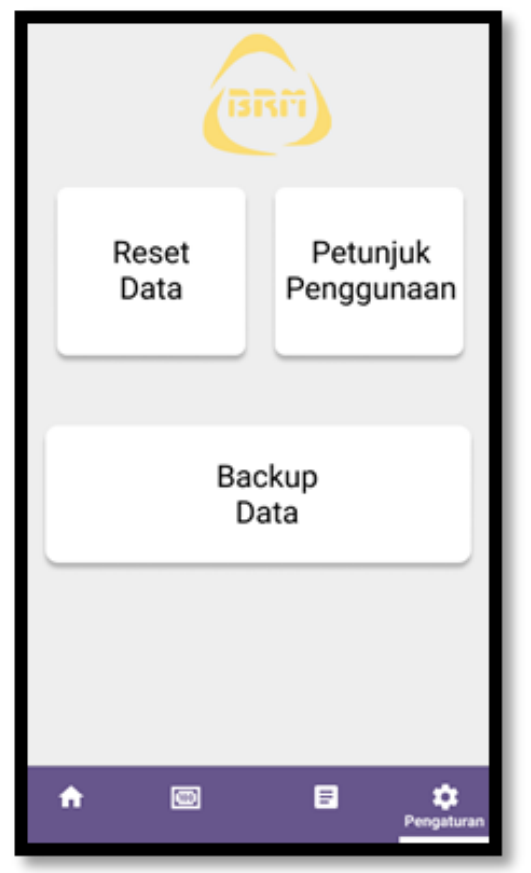

Gambar 8. Konsep halaman menu pengaturan.

Ilustrasi Gambar 8 merupakan desain halaman menu Pengaturan. Di dalam menu utama ini terdapat menu backup data, reset data, dan petunjuk penggunaan.

\section{Pengembangan Aplikasi}

Tahap pengembangan aplikasi merupakan proses kelanjutan setelah konsep desain antar muka aplikasi. Pada tahap ini dilakukan pengembangan dari desain agar dapat menjadi aplikasi siap pakai. Menyematkan fungsi-fungsi aplikasi sesuai dengan kebutuhan di lokasi mitra penelitian.

\section{E. Pengujian Aplikasi}

Proses pengujian pada aplikasi ini dilakukan untuk memastikan sistem yang dibuat berjalan dengan baik sesuai dengan proses yang telah ditentukan. Pengujian yang dilakukan oleh peneliti dengan menggunakan metode Black Box Testing.

Black Box Testing diterapkan pada spesifikasi fungsional dari aplikasi yang dibuat. Tester dapat memfilter berdasarkan kumpulan kondisi input dan melakukan pengetesan pada spesifikasi fungsional program. Hasil dari proses pengujian ini dituliskan pada Tabel 2 berikut.

Tabel 2. Pengujian Black Box.

\begin{tabular}{|c|c|c|c|}
\hline Layout & Antar Muka & $\begin{array}{r}\text { Skenario } \\
\text { Pengujian }\end{array}$ & $\begin{array}{c}\text { Hasil } \\
\text { Uji }\end{array}$ \\
\hline Kategori & $\begin{array}{l}\text { Tampilan } \\
\text { menu } \\
\text { kategori }\end{array}$ & $\begin{array}{l}\text { Menampilkan } \\
\text { data kategori, } \\
\text { menambah data } \\
\text { kategori }\end{array}$ & Sesuai \\
\hline Satuan & $\begin{array}{l}\text { Tampilan } \\
\text { menu satuan }\end{array}$ & $\begin{array}{l}\text { Menampilkan } \\
\text { data satuan, } \\
\text { menambah data } \\
\text { satuan }\end{array}$ & Sesuai \\
\hline Barang & $\begin{array}{l}\text { Tampilan } \\
\text { menu barang }\end{array}$ & $\begin{array}{l}\text { Menambahkan } \\
\text { data barang. }\end{array}$ & Sesuai \\
\hline Harga & $\begin{array}{l}\text { Tampilan } \\
\text { menu harga }\end{array}$ & $\begin{array}{l}\text { Menambahkan } \\
\text { data harga. }\end{array}$ & Sesuai \\
\hline $\begin{array}{l}\text { Informasi } \\
\text { Harga }\end{array}$ & $\begin{array}{l}\text { Tampilan } \\
\text { menu } \\
\text { informasi } \\
\text { harga }\end{array}$ & $\begin{array}{l}\text { Menampilkan } \\
\text { daftar harga } \\
\text { barang. }\end{array}$ & Sesuai \\
\hline $\begin{array}{l}\text { Informasi } \\
\text { Barang }\end{array}$ & $\begin{array}{l}\text { Tampilan } \\
\text { menu } \\
\text { informasi } \\
\text { barang }\end{array}$ & $\begin{array}{l}\text { Menampilkan } \\
\text { daftar barang. }\end{array}$ & Sesuai \\
\hline $\begin{array}{l}\text { Barang } \\
\text { Masuk }\end{array}$ & $\begin{array}{l}\text { Tampilan } \\
\text { menu barang } \\
\text { masuk }\end{array}$ & $\begin{array}{l}\text { Menambahkan } \\
\text { data barang } \\
\text { masuk. }\end{array}$ & Sesuai \\
\hline $\begin{array}{l}\text { Barang } \\
\text { Keluar }\end{array}$ & $\begin{array}{l}\text { Tampilan } \\
\text { menu barang } \\
\text { keluar }\end{array}$ & $\begin{array}{l}\text { Menambahkan } \\
\text { data barang } \\
\text { keluar. }\end{array}$ & esuai \\
\hline Pemasukan & $\begin{array}{l}\text { Tampilan } \\
\text { menu } \\
\text { pemasukan }\end{array}$ & $\begin{array}{l}\text { Menambahkan } \\
\text { data } \\
\text { pemasukan. }\end{array}$ & Sesuai \\
\hline Pengeluaran & $\begin{array}{l}\text { Tampilan } \\
\text { menu } \\
\text { pengeluaran }\end{array}$ & $\begin{array}{l}\text { Menambahkan } \\
\text { data } \\
\text { pengeluaran. }\end{array}$ & Sesuai \\
\hline $\begin{array}{l}\text { Laporan } \\
\text { Barang }\end{array}$ & $\begin{array}{l}\text { Tampilan } \\
\text { menu } \\
\text { laporan } \\
\text { barang }\end{array}$ & $\begin{array}{l}\text { Menampilkan } \\
\text { data barang, } \\
\text { barang masuk, } \\
\text { dan barang } \\
\text { keluar.. }\end{array}$ & Sesuai \\
\hline $\begin{array}{l}\text { Laporan } \\
\text { Pesanan }\end{array}$ & $\begin{array}{l}\text { Tampilan } \\
\text { menu laporan } \\
\text { pesanan }\end{array}$ & $\begin{array}{l}\text { Menampilkan } \\
\text { data barang } \\
\text { keluar. }\end{array}$ & esuai \\
\hline $\begin{array}{l}\text { Laporan } \\
\text { Keuangan }\end{array}$ & $\begin{array}{l}\text { Tampilan } \\
\text { menu } \\
\text { laporan } \\
\text { keuangan }\end{array}$ & $\begin{array}{l}\text { Menampilkan } \\
\text { data pemasukan } \\
\text { dan } \\
\text { pengeluaran.. }\end{array}$ & Sesuai \\
\hline $\begin{array}{l}\text { Grafik } \\
\text { Penjualan }\end{array}$ & $\begin{array}{l}\text { Tampilan } \\
\text { menu grafik } \\
\text { penjualan } \\
\end{array}$ & $\begin{array}{l}\text { Menampilkan } \\
\text { data grafik } \\
\text { penjualan. }\end{array}$ & Sesuai \\
\hline Backup Data & $\begin{array}{l}\text { Tampilan } \\
\text { menu backup } \\
\text { data. }\end{array}$ & $\begin{array}{l}\text { Membackup } \\
\text { semua data } \\
\text { yang tersimpan. }\end{array}$ & Sesuai \\
\hline Reset Data & $\begin{array}{l}\text { Tampilan } \\
\text { menu reset } \\
\text { data. }\end{array}$ & $\begin{array}{l}\text { Mereset ulang } \\
\text { semua data } \\
\text { yang tersimpan. }\end{array}$ & Sesuai \\
\hline
\end{tabular}




\section{F. Penerapan Aplikasi}

Tahap terakhir adalah penerapan aplikasi. Setelah seluruh proses perancangan hingga pengujian aplikasi berhasil dilakukan, selanjutnya aplikasi ini dinyatakan siap untuk digunakan di lokasi mitra penelitian.

Seluruh fungsi aplikasi telah dinyatakan sesuai dengan kebutuhan dari mitra penelitian. Bahkan dengan adanya aplikasi ini dapat mempermudah proses bisnis mitra penelitian.

\section{KESIMPULAN}

Berdasarkan pembahasan dan uraian pada poinpoin sebelumnya, maka dapat diambil kesimpulan sebagai berikut :

1. Implementasi aplikasi untuk memudahkan pencatatan transaksi keuangan dan inventory pada Distributor MSL Purbalingga berhasil dibuat serta telah diterapkan.

2. Penelitian ini telah berhasil membuat aplikasi untuk melakukan pencatatan transaksi dan inventory barang pada Distributor MSL Purbalingga.

3. Aplikasi diuji menggunakan black box testing, untuk mengecek fungsi-fungsi yang terdapat dalam aplikasi Distribusi MSL Purbalingga ini dapat berjalan dengan baik.

\section{UCAPAN TERIMA KASIH}

Peneliti menghaturkan ucapan terima kasih kepada kampus Universitas Amikom Purwokerto dan lembaga LPPM, yang menjadi sponsor sehingga penelitian ini terealisasi.

\section{DAFTAR PUSTAKA}

[1] P. Dhar, "Cloud computing and its applications in the world of networking," $J$. Comput. Sci., vol. 9, no. 1, pp. 430-433, 2012.

[2] C. Wadisman, "PERANCANGAN APLIKASI PENGOLAHAN DATA LOGISTIK PADA KANTOR CABANG BRI SOLOK," Intecoms, vol. 16, pp. 140-150, 2018.

[3] S. Mauluddin and N. Santini, "Sistem Informasi Persediaan Dan Penjualan Barang Berbasis Desktop Di D-Net House Inventory and Sales Information System Base on Desktop at D-Net House," Pros. Saintiks FTIK UNIKOM, pp. 1-6, 2017.

[4] W. M. To and L. S. L. Lai, "Mobile banking and payment in China," IT Prof., vol. 16, no. 3, pp. 22-27, 2014.

[5] H. Huang and G. Gartner, "Current trends and challenges in location-based services," ISPRS Int. J. Geo-Information, vol. 7, no. 6, 2018.
[6] F. Novianto, T. Setiadi, and I. Wahyuningsih, "Implementasi SIKADES (Sistem Informasi Kependudukan Desa) untuk Kemudahan Layanan Administrasi Desa Berbais Web Mobile," J. Inform., 2014.

[7] E. Ahmed, A. Gani, M. Sookhak, S. H. A. Hamid, and F. Xia, "Application optimization in mobile cloud computing: Motivation, taxonomies, and open challenges," J. Netw. Comput. Appl., vol. 52, pp. 52-68, 2015.

[8] J. Yang, Y. Qiao, X. Zhang, H. He, F. Liu, and G. Cheng, "Characterizing user behavior in mobile internet," IEEE Trans. Emerg. Top. Comput., vol. 3, no. 1, pp. 95-106, 2015.

[9] S. H. S, Mudah Membuat Aplikasi Android. Yogyakarta: Andi Offset, 2011.

[10] A. P. Heriyanto, "Procedures and Tools for Acquisition and Analysis of," Aust. Digit. Forensics Conf. Secur. Res. Inst., no. September, 2013.

[11] Andi Juansyah, "Pembangunan Aplikasi Child Tracker Berbasis Assisted - Global Positioning System ( A-GPS ) Dengan Platform Android," J. Ilm. Komput. dan Inform., vol. 1, no. 1, pp. 1-8, 2015. 